EPIDEMIOLOGICAL CHARACTERISTICS OF CHILDREN AND ADOLESCENTS WITH AUTOIMMUNE THYROID DISEASE

A. Papathanasiou' ${ }^{1}$, E. Kousta ${ }^{1}$, K. Anyfandakis ${ }^{1}$, M. Dolianiti' ${ }^{1}$ M. Vakaki ${ }^{2}$, L. Lekka', M. Louraki ${ }^{1}$, C. Kallergis ${ }^{3}$, A. Fotinou ${ }^{4}$

${ }^{1}$ Pediatric Endocrinology, ${ }^{2}$ Radiology, ${ }^{3}$ Department of Dietetics, ${ }^{4}$ Pediatric Microbiology, P \& A.Kyriakou Childrens' Hospital, Athens, Greece

Background/objective: Chronic autoimmune thyroiditis is the most common cause of thyroid dysfunction in children. The epidemiological and clinical characteristics of AT among children differ widely between studies.

To investigate children with AT attending a major Pediatric Endocrinology Unit in Athens.

Methods: Characteristics of 228 children and adolescents (mean $\pm S D$ age: 10.2 $\pm 2.5 \mathrm{yrs}$ ) with AT were assessed retrospectively over ten years. Reasons for referral, family history of thyroid / other autoimmune disease and growth data were recorded. Laboratory evaluation and thyroid U/S scan was carried out in all patients. The patients' characteristics were analysed separately in three groups (euthyroid, subclinical hypothyroid and hypothyroid ).

Results: Main reasons for referral included growth evaluation (23\%), goiter (18\%) and positive family history (17\%).174 patients $(76,3 \%)$ had positive family history and $15(6,6 \%)$ an additional autoimmune disease.191 (83.8\%) were female and $142(62.3 \%)$ pubertal. Among the 228 children, 130 $(57.0 \%)$ were euthyroid, $75(32.9 \%)$ had subclinical hypothyroidism, 19 (8.3\%) hypothyroidism and $4(1.8 \%)$ hyperthyroidism. There was a positive correlation between TSH and thyroid volume SDS $(r=0.15, p=0.02)$. Children with hypothyroidism had higher thyroid volume SDS $(3.1 \pm 1.9$ vs $1.2 \pm 1.2 p<$ $0.05)$ than euthyroid children. Sixty three children $(28 \%)$ had goiter and $32(14 \%)$ had thyroid nodules. Three patients developed papillary carcinoma.

Conclusion: Children and adolescents with AT are mostly asymptomatic; the majority are female, pubertal and euthyroid. Hypothyroid children have higher thyroid volume and increased prevalence of goiter compared to euthyroid children. Diagnosing AT at an early stage gives the opportunity to implement therapeutic measures aiming to prevent disease progression.
407

\section{COMPARISON OF OBESITY AND DIET- RELATED RISK FACTORS FOR CHRONIC DISEASE AMONG MULTI-ETHNIC ADOLESCENT GIRLS}

\author{
A.B. Solomon \\ Public Health, Prairie View A\&M University, \\ Houston, TX, USA
}

Objective: Because chronic diseases disproportionatelyimpactethnicand racial minorities, this study examined differences in dietary intake including snacking and body mass index (BMI) in a multi ethnic sample of adolescent girls to determine potential risk for chronic diseases associated with poor dietary habits.

Methods: Cross-sectional study design in which study participants provided demographic information and completed a food frequency questionnaire - Youth/Adolescent Questionnaire (YAQ). A convenience sample of 198 girls (38\% Mexican American, 34\% African American, and 28\% non-Hispanic white). The study was conducted in a large urban high school in Houston, Texas. BMI was computed as ratio of weight in kilograms and height in meters squared $\left(\mathrm{kg} / \mathrm{m}^{2}\right)$. Dietary intake assessed with YAQ. Multivariate analyses used to determine intake of select nutrients by BMI. Statistical tests were significant at $p<0.05$.

Results: Adjusted BMI was not significantly associated with energy intake $(p=0.071)$. Snacks provided a significant portion (22\%) of total energy intake. Somemacronutrientconsumption differences were evident, an increased consumption of fat by $7 \%$ $(p=0.027)$, sodium by $6 \%(p=0.035)$ and cholesterol by $5 \%(p=0.014)$ among overweight compared to normal weight girls. Significant differences also found in frequency and time of snacking between overweight and normal weight girls.

Conclusions: To effectively address the disproportionate burden of diet-related chronic diseases among minority population, intervention programs should target at risk groups in adolescence or earlier. 